\title{
Until we win la guerra. Transformaciones en la obra de Molina Campos a contraluz del panamericanismo.
}

\author{
Dra. Fabiana Serviddio \\ Universidad Nacional de Tres de Febrero \\ fserviddio@gmail.com \\ Artículo bajo licencia Creative Commons \\ Atribución 4.0 Internacional (CC BY 4.0) \\ ENVIADO: 2019-05-03 \\ ACEPTADO: 2019-06-11
}

\section{RESUMEN}

Este artículo propone partir de un planteo problemático de la obra visual del artista argentino Florencio Molina Campos, y detenerse en el análisis de su colaboración como asesor artístico para la Walt Disney Pictures, en un proyecto fílmico surgido a partir de la Política del Buen Vecino durante la Segunda Guerra. La modificación del carácter de sus imágenes en los años subsiguientes buscó circunscribir las repercusiones simbólicas de las mismas en un escenario conflictivo en el que los intercambios interamericanos debieron sostener las alianzas políticas continentales.

PALABRAS CLAVES

Latinoamérica - Panamericanismo - Molina Campos - Disney - Identidad.

\section{RESUMO}

Este artigo propõe, a partir da problemática do trabalho visual do artista argentino Florencio Molina Campos para analisar a sua colaboração como assessor artístico da Walt Disney Pictures, em um projeto cinematográfico surgido da Política de Boa Vizinhança durante a Segunda Guerra Mundial. A modificação do caráter de suas imagens nos anos seguintes procurou circunscrever as repercussões simbólicas das imagens em um cenário conflitivo no qual as trocas interamericanas tiveram que sustentar as alianças políticas continentais.

\section{PALAVRAS-CHAVE}

América Latina - Panamericanismo - Molina Campos - Disney - Identidade.

\section{ABSTRACT}

This article seeks to present a problematic description of Argentine artist Florencio Molina Campos' visual artworks to analyze his contribution as an artistic adviser for the Walt Disney Pictures, in a film project developed as part of the Good Neighbor policy during the Second World War. The sensitive changes his artworks gained in the following years meant to circumscribe their symbolic repercussions in a conflictive scenario in which InterAmerican interchanges had to back the continental political alliances.

KEYWORDS

Latin America - Panamericanism - Molina Campos - Disney - Identity. 


\section{VIDA DE CAMPO Y AUTORREPRESENTACIÓN NACIONAL}

Atento a la escalada de la ideología filo fascista en Latinoamérica, que tanto en términos políticos como económicos ponía en peligro los intereses norteamericanos en el hemisferio occidental, el gobierno norteamericano reforzó la política panamericanista e implementó, en la inminencia de su ingreso a la Segunda Guerra Mundial, una serie de programas que buscaron mejorar las relaciones con los países latinoamericanos. Esta investigación se enmarca en el campo de estudios de las relaciones culturales interamericanas durante el período señalado (Cramer y Prutsch, 2012; Paquette, 2002; Tota, 2000) y se propone hacer foco en un aspecto aún no suficientemente indagado, relativo a los intercambios en el área de las artes visuales. El caricaturista argentino Florencio Molina Campos participó de los programas de intercambios culturales generados en dicho contexto. El análisis de los estudios críticos a la fecha sobre la producción visual de Molina Campos, y el contraste con material documental recabado en dos reservorios - la Fundación Molina Campos en Moreno, provincia de Buenos Aires y el Museo Las Lilas en San Antonio de Areco-fueron el marco de partida para estudiar su paso por la escena cultural norteamericana, y para proponer una nueva hipótesis sobre la forma y las causas que dispararon modificaciones al estilo de su obra plástica a partir de estas circulaciones. En este aspecto, esta investigación pretende insertarse dentro del amplio espectro de trabajos que se han focalizado en la circulación transnacional de ideas, personas y artefactos como forma de trazar una historia de las relaciones político-culturales entre Estados Unidos y América latina. (Joseph, Legrand y Salvatore, 1998; DaCosta Kaufmann, Dossin, y Joyeux-Prunel, 2015).

Se conoce a Molina Campos por sus incisivas caricaturas de escenas gauchescas, que ya a fines de la década de 1920 permitieron difundir en el país y en el exterior las particularidades de la vida en la pampa argentina, y con ellas fomentar la recuperación de costumbres y valores que parecían perdidos. Con las primeras caricaturas en el diario La Razón y luego las caricaturas gauchescas realizadas para la Exposición Anual de la Sociedad Rural de Palermo, Molina Campos adquirió rápida notoriedad a nivel nacional e inserción en el mercado: el mismo presidente de la nación visitó en 1926 la muestra y compró alguna de sus escenas gauchescas. (Gutiérrez Zaldívar, 2004: 6) Esta difundida anécdota sobre su obra inaugura de algún modo su ingreso en el mercado del arte. El éxito comercial no se tradujo, sin embargo, como en otros casos, en una rápida aceptación por parte de la escena artística cosmopolita. Autodidacta, en los inicios de su práctica como dibujante, el mismo Molina no se pensó a sí mismo como artista. Una vez instalado en Buenos Aires, su producción transitó por algunos espacios de exhibición privados, como la galería Witcomb en Buenos Aires (1933), la rambla de Mar del Plata, el café Tortoni (donde tenía su red de sociabilidad), o el diario El Día de La Plata, pero al margen de las más importantes instituciones de legitimación oficiales -museos y salones-, que configuraron en los años veinte un incipiente campo artístico.

En 1930 la firma Alpargatas lo contrató para realizar una serie de dibujos originales que serían utilizados para producir almanaques publicitarios. De 1931 a 1936, y de 1940 a 1945 , se publicaron 144 almanaques con escenas gauchescas, a partir de aquellos originales. El éxito fue tal, que se llegaron a imprimir 18 millones de ejemplares. Los almanaques se distribuían por miles de ranchos, estaciones y locales de todo el país, donde permanecían como objetos decorativos, lo que convirtió a Molina Campos en el más popular de los artistas argentinos. (Gutiérrez Zaldívar, 2004: 10)

Ya desde las témperas que realizara para la exposición de la Sociedad Rural en 1926, Molina Campos adoptó el estilo de la caricatura política de fin del siglo XIX y lo utilizó cada vez que debía representar la figura. Exageraba los rasgos de sus personajes: agrandaba sus bocas, dentaduras, ojos - que a veces adoptaban forma esférica- y narices - de tonalidad rojiza, rasgo que se ha interpretado como aquel propio del bebedor frecuente-, y de la misma forma caricaturizaba las figuras de caballos, avestruces, perros, y toros, compañeros inseparables de los gauchos en el mundo rural. También exacerbaba ciertos rasgos físicos de los personajes como pies, manos y a veces cabezas, en una codificación claramente filiada de la caricatura periodística. Si el género paisajístico se había transformado durante el siglo XIX en una clave visual y literaria para perfilar los rasgos de las nacientes identidades nacionales en Latinoamérica, en la obra de Molina Campos la unión estructural entre el medio humano y el natural que supuso la caricaturización de todos sus seres vivos -sean estos humanos o animales- 
asignó al gaucho el rol central del gran teatro de la pampa, y convirtió a sus imágenes en íconos de "argentinidad", en los que cada elemento está indisociablemente atado al otro.

Los artistas extranjeros y nacionales del siglo XIX tuvieron una fuerte impronta en su trabajo, y esto se hace evidente en la forma de representar el paisaje de llanura mediante una perspectiva aérea que pintaba en sus varias alternativas climáticas, horarias, topográficas (Monzón, Florencio Molina Campos), sugiriendo lejanía y con la fórmula usual del formato apaisado que puede apreciarse en las obras de artistas como Prilidiano Pueyredón o Eduardo Sívori. Sin embargo, fiel al estilo propio de la caricatura, en sus obras tempranas Molina Campos tiende a concentrar la atención en la acción de los personajes que se desarrolla en primer plano, aumentando el tamaño de las figuras en relación al fondo que las contiene.

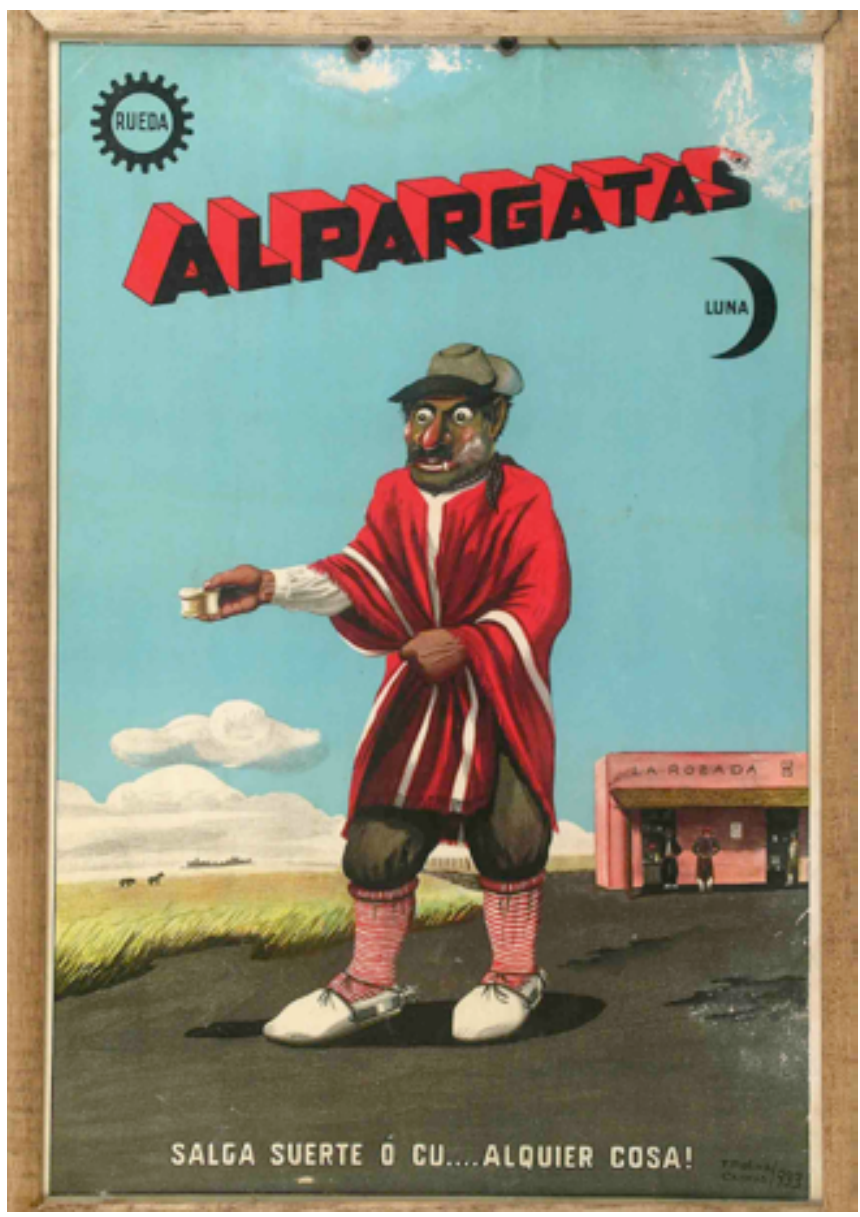

Figura 1. Florencio Molina Campos, Salga suerte o cu... alquier cosa!, afiche reproducción de almanaque lanzado por la empresa Alpargatas, 1933. Fundacion Florencio Molina Campos, Moreno, Provincia de Buenos Aires, Argentina.

La historiografía de su obra ha tendido a uniformizar rápidamente su producción, destacando un estilo distinguible y casi inmutable en el tiempo; sin embargo, es posible discernir, hacia fines de los años treinta, el desarrollo de distintos registros estilísticos, que adaptó de acuerdo al soporte y la funcionalidad de la pieza. Hubo ocasiones en las que optó por ceñirse a ciertos géneros y adoptar estilos francamente naturalistas: el artista elegía en qué momentos volcar hacia lo caricaturesco la representación. Estos distintos registros estilísticos pueden apreciarse aún entre piezas contemporáneas entre sí: las elecciones se adecuaron no sólo a la funcionalidad para la que estaba pensado el dibujo, sino también al medio de circulación: clave, como veremos, será si estaban destinadas a la escena local, o a exhibirse en los Estados Unidos, y en qué período de su estadía fueron realizadas.

En los inicios de su carrera como dibujante Molina Campos encontró en la caricatura una herramienta para inyectar verismo a la representación física del gaucho en tanto sujeto mestizo, cuestión invisibilizada en la mayoría de los personajes presentes en pinturas de la pampa argentina del siglo XIX-. La caricatura fue su primera herramienta profesional y de ella se sirvió para modificar una idea prestablecida sobre el gaucho y la vida de campo. Sin embargo paulatinamente fue enriqueciendo sus habilidades plásticas, y esto le permitió adoptar ciertas decisiones sobre la calidad expresiva de las imágenes.

Los almanaques de la serie 1940-1945 estaban provistos de refranes y leyendas, que unidos a ese rescate del campo como lugar de lo incontaminado o del pasado idealizado proyectaban cierto espíritu moralizante. Este discurso moral también había sido una constante en las narraciones gauchescas del siglo XIX y Molina Campos lo recuperó como componente narrativo esencial para revalorizar la vida rural. En efecto, formaba parte del sustrato ideológico del movimiento de reivindicación tradicionalista llevado adelante con éxito por parte de una coalición de agrupaciones militares y civiles, que a través de la oficialización del Día de la Tradición en 1938 logró la institucionalización de la figura del gaucho como arquetipo de la nacionalidad argentina, protector ante elementos extranjerizantes, disolventes de la unidad nacional. (Casas 2017)

Las máximas y consejos iban en la parte de atrás de las láminas: prudencia en el beber, no pelear. Otras veces era Tiléforo Areco el narrador testigo encargado de escribir postales llenas de buenas intenciones para la época de las fiestas: se trataba de un personaje ficcional creado ad hoc por el artista, un peón de campo que seguía los requerimientos de su "patrón” Molina Campos.

Ser gaucho representaba un compromiso con la honradez, la lealtad, la valentía, la pureza viril. (Bonomini, 1989: 50; Molina, 1989: 3) Son múltiples las relaciones posibles de establecer con la pintura de costumbrismo rural del siglo XIX, derivada de la literatura gauchesca, cuyo espesor ético el mismo artista señaló como principal referente de su obra. En un reportaje para la revista Cine mudo Molina Campos afirmaba:

Yo he querido que el espíritu heroico y nobilísimo de nuestros gauchos de antaño no desaparezca de entre nosotros, arrollado por el embate materialista y grosero del modernismo; que no se borre jamás la fuente inspiradora de nuestra nacionalidad; y humildemente, a la zaga de Martín Fierro, de Santos Vega y del Fausto argentino, los cantos máximos del alma gaucha, voy manteniendo vivo el fuego a ese culto. El gaucho se va. Lo ha desalojado el modernismo y vive ya solo en la leyenda. Pero confío en que, al darle forma gráfica, se adentre de nuevo en nuestra vida de hoy y de siempre, como lo estuvo en nuestro glorioso pasado. (Ocampo, 2003: 76)

En la tónica de los tradicionalistas, sus dibujos encierran cierto desdén hacia el proyecto de la generación del 80 y la imposición de una nueva escala de valores alejada de los preceptos éticos del hombre rural. Así dejan la sensación de estar rechazando críticamente, a través de la ironía visual, la contaminación cultural y de valores introducidas por el componente inmigratorio. 
Si para Bonomini el tono burlón se entendería por la complicidad con sus personajes, para Monzón en cambio, se trata de la mirada de un hombre que al igual que Ricardo Güiraldes, observa con amor y respeto a la existencia rústica, a través de la ideología de un empinado estrato social. (Monzón s/f). Desde la perspectiva de Enrique Molina, la relación es dual, una mezcla de "afectuosidad burlona y profunda identificación con ese medio y sus seres". (Molina, 1989:3)

Sus representaciones más realistas mantuvieron una visión idealizada del gaucho y al mismo tiempo lo situaron en el corazón de los conflictos nacionales, atravesado por la lucha por el territorio, debatiéndose entre un estilo de vida reglado y subyugado a la nación, y otro que dignificaba como máximo valor la libertad. El mundo rural retratado por Molina aparece en una primera lectura como un mundo feliz, sin conflictos - escenas que, como varios críticos de su obra han notado, en los años 20 ya no existían-, pero es precisamente el tamiz humorístico que le imprime lo que permite que de las imágenes emerjan las tensiones raciales, sociales y políticas que habían fundado la nación.

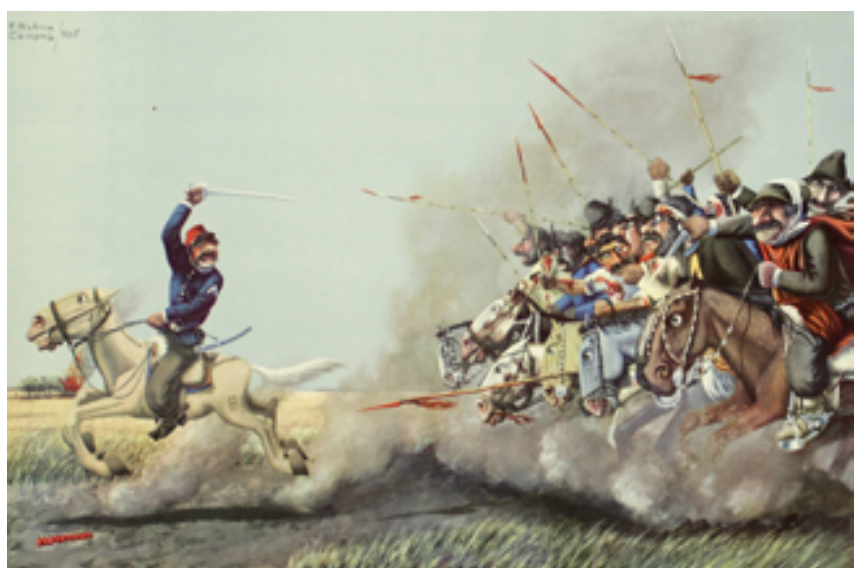

Figura 2. Florencio Molina Campos, Estas no son flores... caracho!, ilustración para almanaque de Alpargatas, 1935. Fondo Florencio Molina Campos, Biblioteca del Museo Las Lilas de Areco, Provincia de Buenos Aires, Argentina.

Si en su fisionomía el gaucho roza a veces el grotesco, en sus vestimentas está descrito cuidadosamente, con todos los detalles del apero criollo totalmente fidedignos. Molina Campos recupera una iconografía tradicional costumbrista, a la cual le suma nuevos elementos, como la alpargata y la boina de vasco, de la mano de personajes recientemente llegados al campo, los inmigrantes. A través de estos recursos el artista acercó la imagen del gaucho a un tiempo más contemporáneo con una representación verosímil de los detalles de su vestimenta y de sus actividades diarias, aun si el actor histórico que representaba ya había sido absorbido dentro de la estructura socioeconómica de explotación de los campos argentinos.

Otro recurso que trae las caricaturas de gauchos a un tiempo mucho más actual es la creación -antes mencionada- de personajes con nombre y apellido y particularidades fisiognómicas que permiten individualizarlos y reutilizarlos en una y otra escena. Se trata de figuras cuyas historias de vida se suceden en las imágenes que ilustran cada serie anual de almanaques a lo largo de doce meses, como la historia de Tiléforo Areco. Su vida es representada a lo largo de las imágenes que ilustran los doce meses del almanaque de 1942. El almanaque atraviesa todas las etapas en las que su vida se encauza hacia lo que la sociedad reglada espera de él: el asentamiento en un hogar, su casamiento y el nacimiento de sus hijos se narran en la sucesión de ilustraciones. Construyó así un tipo complejo, un personaje intrínsecamente atravesado por tensiones temporales, a medio camino entre sujeto abstracto y personaje real. Un ideal ético, encarnado en personajes verosímiles.

El mismo artista personificó a través de autorretratos pictóricos y fotográficos el tipo gauchesco, convocando esa identidad en un juego intencional de autoidentificación con sus propias creaciones, entre la celebración de su figura y el rédito comercial, en el que "lo gaucho" abandonaba su lugar de tipo social históricamente inscripto para convertirse en un rasgo moral que lo definía: el "alma de gaucho". Un ejemplo sugestivo fue la sesión fotográfica realizada en el estudio de fotografía Shonfeld en 1933, cuando se le propone jugar a adoptar la identidad gauchesca para retratarse.

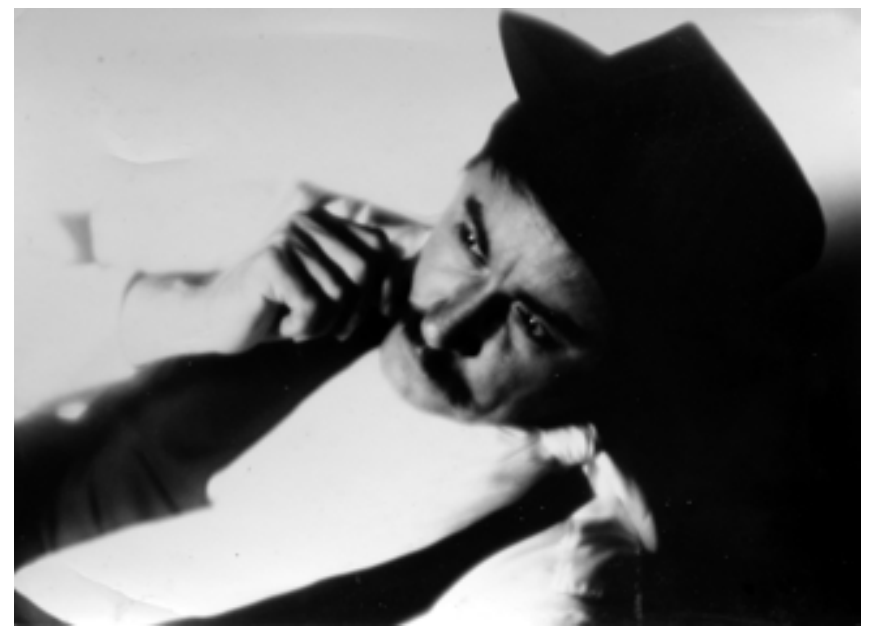

Figura 3. Estudio Nicolás Schonfeld, Florencio Molina Campos, $18 \times 13,1933$ Registro 1363, Fondo Florencio Molina Campos, Biblioteca del Museo Las Lilas de Areco, Provincia de Buenos Aires, Argentina.

También en P'al retrato, el artista se autorepresentó en vestimenta gaucha posando junto a un viejo amigo (personaje de sus ilustraciones) ante un paisaje pintado que los sitúa en un ambiente rural, durante una sesión fotográfica en la que todos los elementos (la iluminación, la columnilla con una planta encima, las posturas rígidas) apuntan a subrayar la artificialidad de la escena; la témpera se transforma así en un comentario metarreferencial sobre el gran dispositivo simbólico que constituye el corpus de obra en su totalidad.

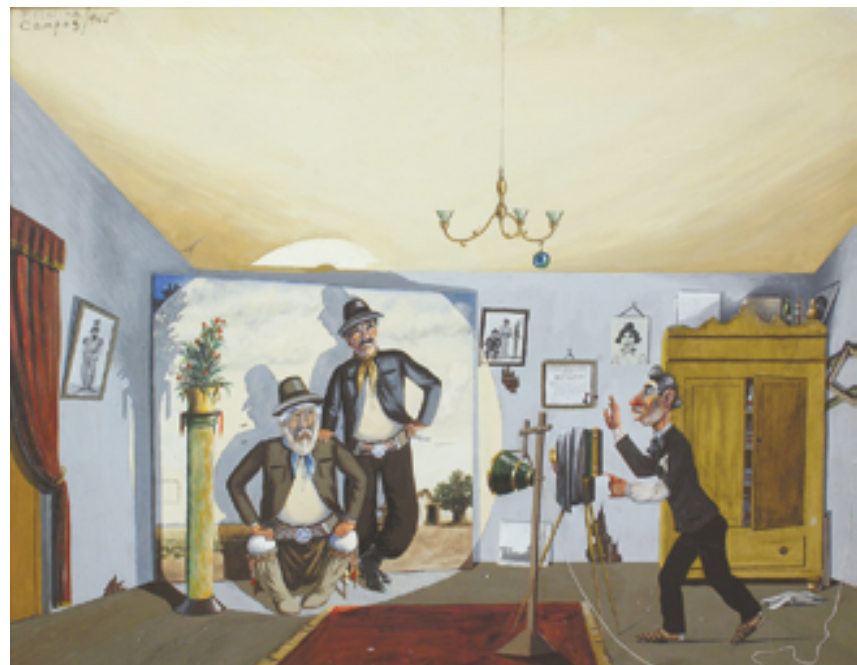

Figura 4. Florencio Molina Campos, $P$ ' al retrato, témpera sobre papel, 38 x 47, 1945. Fundación Florencio Molina Campos, Moreno, Provincia de Buenos Aires, Argentina. 


\section{LAS ANDANZAS DE UN TRUE GAUCHO EN USA.}

En 1938 Molina Campos viajó por primera vez a EEUU. gracias a una beca de la Comisión Nacional de Cultura, para realizar estudios de animación de dibujos. En Nueva York conoció al publicista Joshua Powers, quien se convirtió en su amigo y representante comercial. A través de Powers, Molina Campos consiguió contratos publicitarios, exposiciones y ventas en esa ciudad, en Nuevo México y en California [Ocampo, 2003: 22-26].

Su vida profesional transcurrió a partir de ese momento entre la Argentina y los Estados Unidos. La coyuntura internacional planteaba un escenario claramente prebélico: el avance de las fuerzas nazis en Europa del este indicaba que iba a ser casi imposible evitar una segunda guerra mundial y no tomar partido en el conflicto, y esto repercutió irremediablemente en las relaciones interamericanas. La Política del "Buen Vecino", inaugurada oficialmente a inicios de 1930 por el presidente Roosevelt como giro en la estrategia imperialista con las naciones latinoamericanas, tomó por lo tanto a fines de la década un cariz cada vez más antifascista: se temía que la avanzada alemana no se detuviera en Europa. Si bien la Argentina fue de los países latinoamericanos que más habían resistido la embestida panamericanista desde principios de siglo por la filiación europeísta de sus intelectuales y políticos, por la competencia comercial continental que ésta suponía a sus intereses (Morgenfeld, 2007), y mantuvo su neutralidad durante el conflicto bélico, el vínculo con artistas e intelectuales de este país no se descuidó.

A su llegada a los Estados Unidos, Molina Campos encontró un contexto ampliamente favorable a la recepción amistosa de emisarios latinoamericanos que pudieran contribuir a mejorar las relaciones hemisféricas. Una coyuntura histórica ideal para transformarse en representante argentino de los buenos vínculos interamericanos, junto a otros escritores, músicos, y artistas que promovieron la confraternidad interamericana, resignificando en sus propios términos la invitación panamericanista, a sabiendas de que cumplían con una misión diplomática que les posibilitaba, además, su práctica profesional en los Estados Unidos, donde daban a conocer su obra a un nuevo público. La convicción en la causa de los Aliados era, por otra parte, el punto de partida que los unía a favor de la lucha por la libertad y autodeterminación de los pueblos. A partir de esta confraternidad de ideas, fue que gran parte de la producción plástica de Molina Campos realizada en Norteamérica tuvo un sesgo ideológico manifiestamente inscripto a favor del panamericanismo.

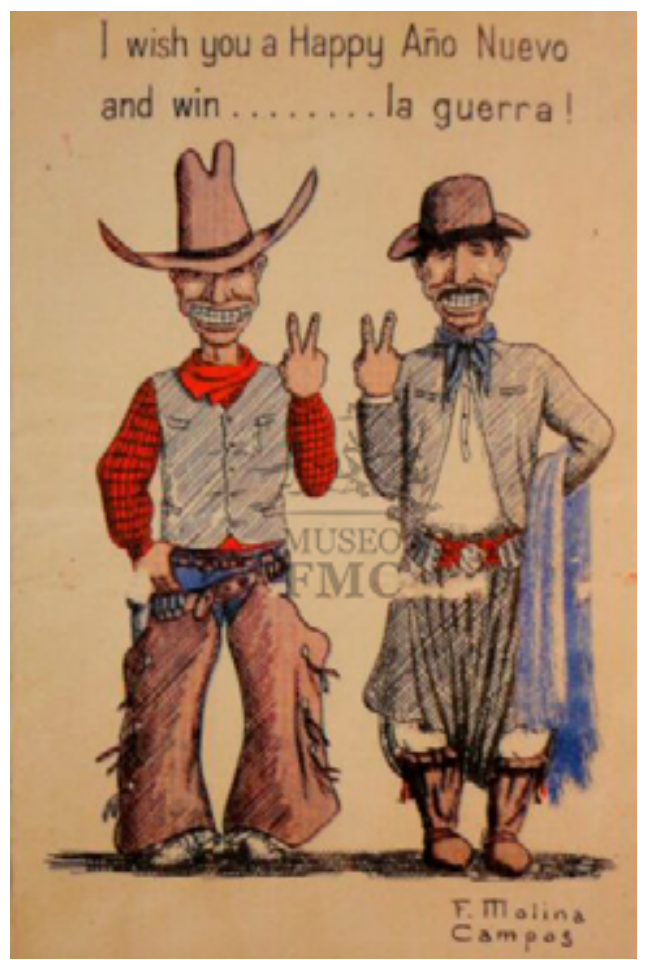

Figura 5

Florencio Molina Campos, I wish you a Happy Año Nuevo and win... la guerra!, tarjeta de salutación, 21, 5 × 14 c. diciembre 1942 Fundación Florencio Molina Campos, Moreno, Provincia de Buenos Aires, Argentina.

El artista dictó conferencias sobre la Argentina en diversas universidades, realizó ilustraciones y relatos para revistas de interés general como Liberty y Life, exhibió sus témperas en el English Book Shop de Nueva York y en la Universidad de Washington, ilustró afiches de cine; difundió su obra y con ella los usos y costumbres de la vida del gaucho argentino a través de todo medio al que tuvo acceso. Algunos cuentos e ilustraciones, por ejemplo las Andanzas de un gaucho en Nueva York, planteaban situaciones inéditas y humorísticas que hacían colisionar costumbres cosmopolitas y rurales, norteamericanas y argentinas, como la de un gaucho montado en su caballo y extrapolado en un contexto cosmopolita y extranjero, visitando Times Square y Central Station (Erskine, 1942). En relación a estas ficciones de encuentros eventuales entre costumbres y personajes en apariencia tan disímiles, Molina Campos creó un nuevo personaje ad hoc, Lindor Pinto, un gaucho de facciones y vestimenta mucho más sofisticados que aquellos peones de clase baja que poblaban las ilustraciones de los almanaques de Alpargatas.

Figura 6

Florencio Molina Campos, Lindor Pinto en Central Park, $27 \times 38$, témpera sobre cartulina. Fondo Florencio Molina Campos, Biblioteca del Museo Las Lilas de Areco, Provincia de Buenos Aires, Argentina.

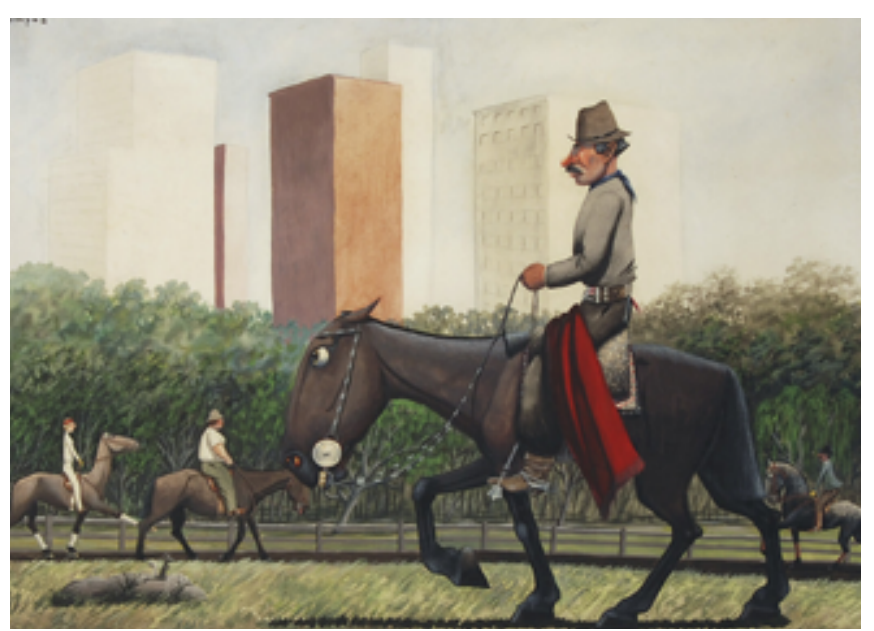


Esta primera inflexión en el estilo de sus nuevas creaciones señala un cambio de actitud a tener en cuenta. De esto y otros elementos que veremos más adelante, ya inducimos que en esta nueva etapa de trabajo en otra escena cultural, la expectativa por la forma en que interpretarían los norteamericanos costumbres y tipos tan extraños a los propios era una preocupación importante para Molina y un momento en el que parece haber decidido que el suyo no iba a ser el rol de un artista más sino el de un diplomático cultural. En esta etapa Molina Campos ilustró también Vida Gaucha, un texto para estudiantes de español en Estados Unidos, en el que reutilizó algunas témperas con escenas gauchescas creadas para la firma Alpargatas y tuvo un programa de radio donde asumía la voz ficcional del gaucho Lindor para relatar con humor las diferencias entre la vida rural y la metropolitana, y sus impresiones frente a ello. De esta manera fomentó todo tipo de actividades de intercambio cultural que le plantearon a la audiencia continental ejercicios permanentes de similitud y contraste con sus propios usos y valores, a partir de una construcción de la idea de nación argentina que presentó sin embargo un recorte sesgado.

En el contexto arriba mencionado, las exhibiciones artísticas organizadas por el gobierno norteamericano o por instituciones afines a éste también se concibieron a partir de las urgencias diplomáticas, y apuntaron ante todo a convencer a los vecinos latinoamericanos de la necesidad de cerrar filas con la causa Aliada. En algunas, los objetivos se expusieron de forma más abierta, como en el caso de Carteles: Un Hemisferio Unido, el concurso organizado por el Museo de Arte Moderno de Nueva York en 1942 abierto a artistas de todo el continente. En este concurso Molina Campos fue especialmente invitado a participar.
El museo propuso 12 lemas posibles a partir de los cuales, a elección, el artista interesado creaba su cartel. El objetivo explícito de la muestra era exponer el sentimiento de unidad del hemisferio y el común espíritu de lucha contra la agresión nazi, mediante la expresión artística de "la común determinación de permanecer libres que alienta en las naciones de América." ${ }^{2}$ Molina Campos participó en ese concurso con un cartel de características estilísticas completamente ajenas al estilo caricaturesco por el que se había hecho famoso. Tuvo en estudio varios bocetos: en uno de éstos daba una fuerte impresión de dinamismo mediante la representación de dos caballos en brío enfrentados, montados de un lado por el cowboy norteamericano, del otro por el gaucho argentino. Finalmente sin embargo optó por una composición mucho más estática y sin carga expresiva alguna, en la que los dos jinetes montados sobre caballos en suave galope extienden sus manos para estrecharlas, opción plásticamente inocua a la más mínima posibilidad de percepción de conflicto latente. El cartel recibió el cuarto premio del concurso, y fue reproducido en el catálogo.

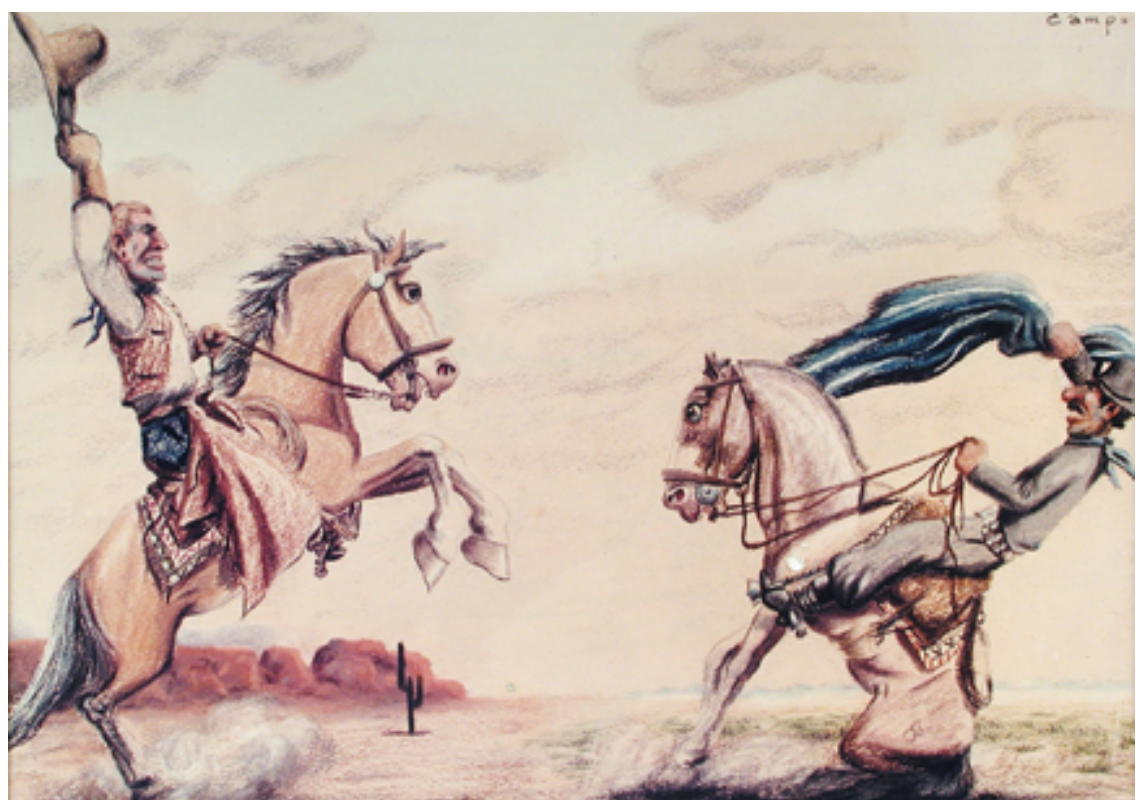

Figura 7. Florencio Molina Campos, Latinoamérica unida y en paz, dibujo sobre papel. Registro 1669 , Fondo Florencio Molina Campos, Biblioteca del Museo Las Lilas de Areco, Provincia de Buenos Aires, Argentina.

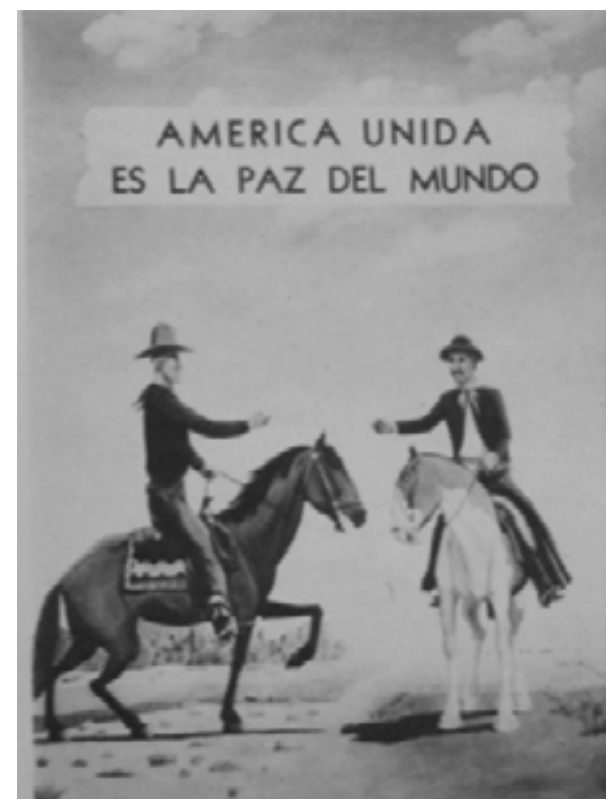

Figura 8. Florencio Molina Campos, América unida es la paz del mundo, concurso Carteles: Un Hemisferio Unido, MoMA, Nueva York, 1942. Reproducción de imagen de catálogo. 4to premio. 
Sin embargo, de todas las invitaciones recibidas por Molina Campos para participar en proyectos vinculados a la política de propaganda panamericana del gobierno estadounidense, la más notoria como se sabe fue la extendida por la Walt Disney Pictures. En 1941, Walt Disney había recibido la solicitud de parte del gobierno de colaborar con la causa patriótica y realizar una gira de amistad por países de América del Sur. Fue en ese año que se selló un convenio entre la compañía y la Oficina del Coordinador de Asuntos Interamericanos, agencia oficial liderada por Nelson Rockefeller creada con el propósito de subvencionar programas culturales, educativos y científicos como parte de la política de diplomacia interamericana que buscaba mejorar las relaciones entre Estados Unidos y Latinoamérica durante la Segunda Guerra. La oficina del Coordinador de Asuntos Interamericanos profundizó las acciones ya iniciadas tiempo atrás con la denominada "política del Buen Vecino", que tenía como objetivo exportar una imagen más positiva de Estados Unidos hacia América latina, y modificar ideas preconcebidas sobre ésta (Smith, 1976: 79, en Adams, 2007: 291). La Motion Picture Division concentró sus esfuerzos en disciplinar a la industria hollywoodense para que no se siguieran difundiendo imágenes estereotípicas negativas de los latinoamericanos. El mandato era directo y simple: no importaba de qué género se tratara, debía asegurarse de que absolutamente todas las películas de Hollywood estuvieran libres de cualquier insinuación que pudiera ser considerada potencialmente ofensiva hacia las "sensibilidades latinas”. (O’Neill, 2001: 359 en Adams, 2007: 291).

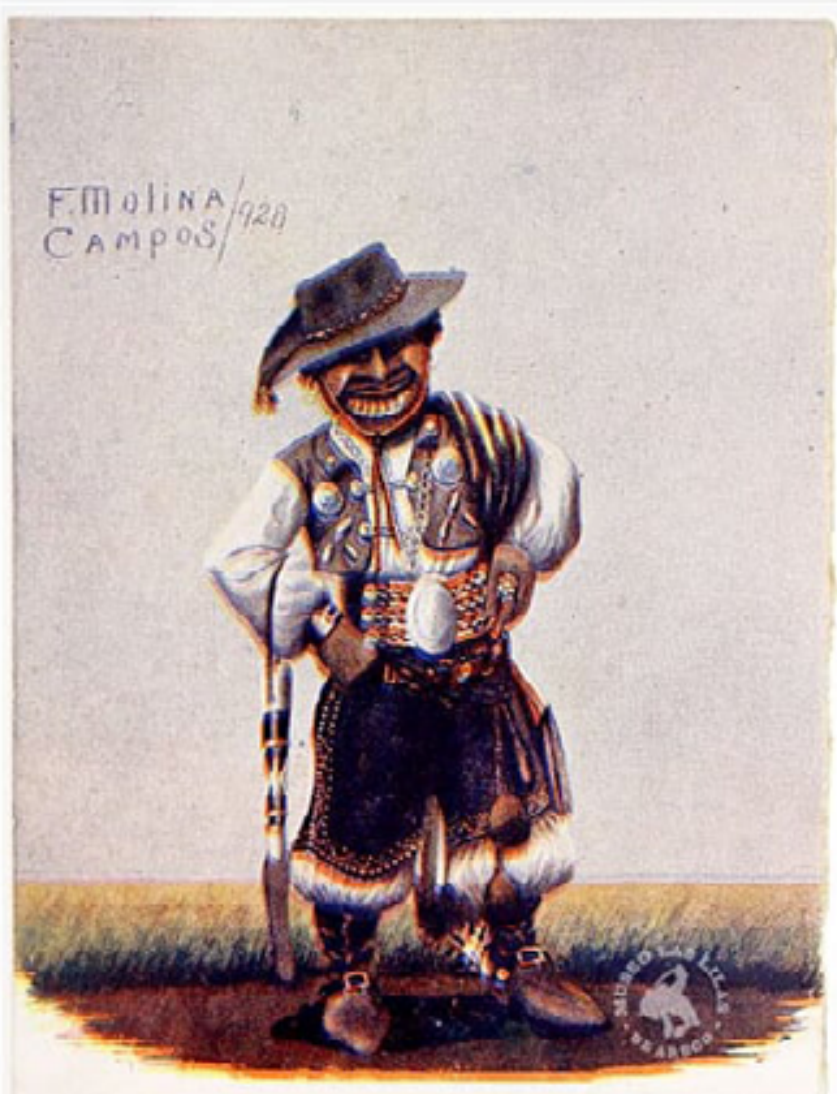

THE GAUCHO
El desafío para el estudio Disney fue no caer en los errores cometidos por las otras productoras cinematográficas de Hollywood: producir cortos animados que pudieran llegar también al público latinoamericano, dentro de un marco de respeto inobjetable de sus costumbres de vida, y sin traicionar el estilo "Disney" tan popular y exitoso. El mismo Molina Campos se contaba entre los críticos latinoamericanos a las interpretaciones ridículas de las producciones hollywoodenses. Sus caricaturas surgieron también de la necesidad de corregir las miradas extranjeras hacia la cultura local. La primera serie de postales que imprimió en Buenos Aires la firma Moen en 1928 tenían una intención pedagógica y crítica, en la que el artista apuntó directamente a enmendar la tergiversación del gaucho de la película muda The Gaucho (1927), producida y protagonizada por Douglas Fairbanks padre y distribuida por la United Artists. En ella el protagonista interpretaba a un personaje pendenciero, con vestimenta mezcla de torero y charro, basado más en la figura del forajido héroe característico de los corridos mexicanos. Esta versión hollywoodense creaba un relato atractivo para las grandes audiencias, lleno de aventura, ambientes exóticos y personajes fuera de la ley que lograban salirse con las suyas, lo que de acuerdo a Molina Campos distorsionaba el específico tipo gauchesco. (Ocampo, 2003: 73)

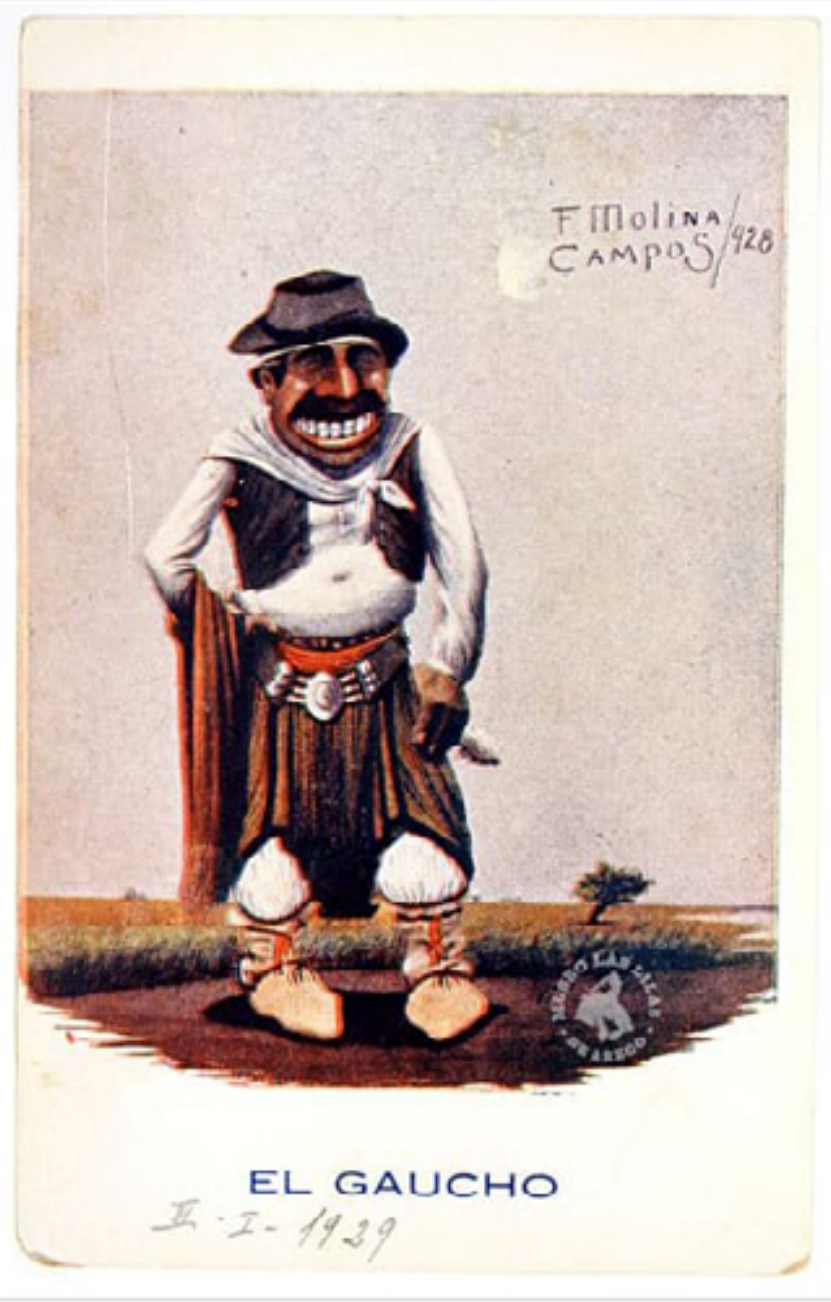

Figura 9. Florencio Molina Campos, The gaucho / El gaucho, postales, 1928. Fundación Florencio Molina Campos, Moreno, provincia de Buenos Aires, Argentina. 
También en Argentina la circulación de una literatura todavía ligada a los folletines del siglo XIX donde los gauchos eran tipos pendencieros seguía entusiasmando a los sectores populares (Adamovsky, 2019), de modo que, como ya señalamos, el claro posicionamiento de Molina Campos contra este tipo de representaciones se insertaba en debates más profundos referidos a la figura del gaucho como símbolo de la identidad nacional.

Como ha señalado ya Allen Woll y demuestran los documentos de archivo de la época, Hollywood comenzó a mirar hacia Latinoamérica también para obtener alivio económico, para compensar la pérdida de los ingresos del exterior que la Europa en guerra imposibilitaba, y fue tras esta porción del incipiente nuevo mercado. Por lo tanto, la intervención del capital de la industria fílmica en la política del Buen vecino fue más que un gesto patriótico en respuesta a la presión gubernamental. (Woll, 1974: 282) Al igual que los otros empresarios de la industria de Hollywood, Disney necesitaba diversificar su producción, abrir nuevos mercados de distribución y crear nuevos intereses para subsanar las pérdidas que la guerra en Europa había traído a la industria cinematográfica local. Aceptó de buen agrado por lo tanto la propuesta de colaborar con el gobierno y organizó varios viajes con su equipo de dibujantes para recabar motivos nuevos y característicos que le permitieran la realización de algunos cortos animados, y además la experimentación con nuevas tecnologías de la imagen que ensamblaban fragmentos documentales con fragmentos animados. El primer viaje se concretó en 1941 y el equipo de dibujantes y músicos visitó Argentina, Uruguay, Brasil, Chile, y la zona andina. Molina Campos se encontró con Walt Disney en Río de Janeiro y allí éste lo invitó formalmente a colaborar con el estudio asesorándolo en la creación de algunos cortos que iban a abordar las costumbres campestres argentinas de manera humorística.

Los films animados desarrollados por el estudio Disney para la Oficina del Coordinador fueron numerosos pero en este trabajo me centraré en Goofy se vuelve gaucho, uno de los cortos incluidos en el primero de los dos más importantes films de animación producidos y distribuidos durante el período de guerra, Saludos Amigos, para analizarlo en relación a la participación de Molina Campos en dicho proyecto. Saludos Amigos es un largometraje que inicia la narración con algunos fragmentos del documental de la gira de Walt Disney y su equipo de dibujantes por varios países de Latinoamérica, y la voz en off de un narrador va entretejiendo estas escenas con cuatro cortos animados: Donald en el lago Titicaca, Pedro el avioncito, Goofy se hace gaucho, y Acuarela do Brasil. Se suceden así tramos documentales, vistas de bocetos realizados por los dibujantes y los cortos animados en sí mismos.

En uno de esos tramos, se documenta la visita de Disney y sus dibujantes al estudio de Molina Campos en Moreno, ocasión en la cual se ve al artista exhibiéndoles varias de sus témperas de gauchos, realizados "con mucho detalle y mucho buen humor". La voz en off del narrador explica que de aquí había surgido la inquietud de ver a los gauchos mismos en acción, por lo que parten a asistir a una doma y luego a comer un asado y a disfrutar la exhibición de danzas folklóricas. El relator cuenta que "no pudimos evitar compararlas con la vida del cowboy: sus vidas tienen mucho en común". Goofy se vuelve gaucho va a intentar entablar paralelismos entre las costumbres rurales argentinas y las del cowboy norteamericano, y así establecer una plataforma de valores éticos en común propia del continente americano (honestidad, sencillez, simpleza, trabajo duro) que expresaran la pertenencia de latinos y norteamericanos a una comunidad continental hermana, explotando la potencialidad de la propaganda política a partir del carácter humorístico de sus caricaturas. Como vimos, desde su llegada a los Estados Unidos, el mismo Molina Campos ya había puesto en práctica a través de sus dibujos y actividades culturales paralelas este juego de similitudes y contrastes entre el gaucho y el cowboy. Esa táctica narrativa se descubre en muchos otros formatos discursivos como exposiciones, concursos, o convocatorias a realizar proyectos artísticos, y en la misma filmografía de Buenos Vecinos, que puso en paralelo situaciones disímiles para generar empatía con "el otro". ${ }^{3}$

El guion hizo asumir a Goofy, cowboy trasplantado a las pampas, las vicisitudes de alguien que intentara realizar las arduas tareas del gaucho pampeano. Goofy resulta desastroso a la hora de perseguir y enlazar al pingo, de controlar con las boleadoras los avestruces, de domesticar a su propio caballo -que termina dándole vuelta su apero y usándolo como cama-. Él encarnaba el costado ridículo de quien intenta asumir un papel que no le corresponde. El film partía de un imaginario previo que reconocía falso: "algunas cualidades de la vida del gaucho según le aparecen al hombre norteamericano a través de libros y films han creado la fantasía de una vida de gaucho romántica y glamorosa", sostenía el relator.

Sin embargo, los mismos investigadores de la historia fílmica de la Disney prueban que los hechos no se sucedieron de la forma que plantea el relato del corto animado. La compañía ya venía preparando una serie de estudios dedicada a la figura del gaucho mucho antes de que Walt Disney y su equipo de dibujantes realizaran el viaje sudamericano. El estudio estaba bajo mucha presión para producir y sacar a circulación "films del buen Vecino" lo más pronto posible, y por ese motivo contactó a Jack Kinney, quien había dirigido los exitosos cortos How to, en los que Goofy intentaba demostrar la manera correcta de montar un caballo, o practicar un deporte, con resultados desastrosamente hilarantes. En ese momento se consideró que Goofy era un personaje ideal para protagonizar el corto argentino, puesto que la audiencia norteamericana ya lo conocía, y sabía que su rasgo característico era arruinar cualquier tarea que se propusiera. Por eso, se quiso mostrarlo, primero, explícitamente como un cowboy norteamericano, que era luego transportado rápida y mágicamente a las llanuras argentinas, donde intentaría torpemente convertirse en un verdadero gaucho. Nadie -imaginaron los productores- podría interpretarlo como un intento de ridiculización de los argentinos o de los gauchos reales... (Kaufman, 2009: 83) Para la creación del corto se recabó efectivamente mucho material de los bocetos y notas realizados por el equipo de dibujantes de Disney a partir de los dibujos de Molina Campos en su estancia Los Estribos en Moreno, provincia de Buenos Aires..$^{(K a u f m a n, ~ 2009: ~ 86) ~ D e ~ l o s ~ c a l e n d a r i o s ~}$ de Alpargatas se adoptaron principalmente los fondos: la perspectiva de horizonte bajo, que permitía una lectura mucho más clara de la acción animada, fue una de las características del estilo de Molina Campos que más entusiasmó a los dibujantes. (Kaufman, 2009: 85)

Para cuando el artista llegó a los estudios Disney en Burbank, California, esperando tomar las riendas del film -finales del

El film Good Neighbor family, de Julien Bryan o su más conocida Americans All son ejemplos característicos de estas estrategias narrativas.

$4 \quad$ El libro de Kaufman está basado en los archivos de la corporación Disney en los que están alojados los materiales documentales. El autor observa que las secuencias de este corto siguen muy de cerca las caricaturas de Molina Campos en cuanto a los detalles descriptivos de vestimentas y accesorios, y también en relación al acompañamiento musical, cuyas melodías se confiaron a Andrés de Chazarreta, autoridad en estilos musicales rurales de Argentina. 
mes de marzo de 1942-, los lineamientos fundamentales de los cortos argentinos ya estaban trazados y animados. Al artista se le exhibieron las películas en crudo de El gauchito volador y Goofy se vuelve gaucho. Los involucrados en el proyecto atestiguan que, frente a esa situación tan desalentadora, inmediatamente comenzó a señalar todos los errores que veía (Kaufman, 2009: 85). Era, por supuesto, totalmente improbable que su sola presencia y voluntad fuera a torcer el brazo de un equipo de producción con un estilo y dinámica de trabajo tan consolidados y exitosos en la década del cuarenta como era el de la Disney, pero aún así las cosas, la decepción de Molina Campos fue grande.

Las escenas le resultaron "grotescas", "arbitrarias", y sensacionalistas. (Ocampo, 2003: 78) Él concebía al cine como el instrumento educativo por excelencia en la época contemporánea. Su idea fue inmediatamente "hacerles comprender la verdadera figura del paisano argentino" -lo que a los dibujantes les resultó, por lo menos, sorprendente y gracioso-. Quedaba claro que lo que realizaría Disney no serían documentales; insertos dentro de los engranajes de la industria cultural, su objetivo primordial era el éxito popular. Si bien cumplieron con todos los requerimientos necesarios para satisfacer a un emisario latinoamericano que venía a trabajar en el contexto del programa de Buena vecindad, llevándolo a funciones especiales, galas y atendiendo a sus sugerencias, los cortos mantuvieron el carácter fantástico y cómico que se había pensado desde el inicio para ellos. Molina Campos corrigió estos dibujos realizando ajustes en lo que respecta a los detalles de la vestimenta del gaucho, sus instrumentos para la actividad campestre y la montura del caballo.

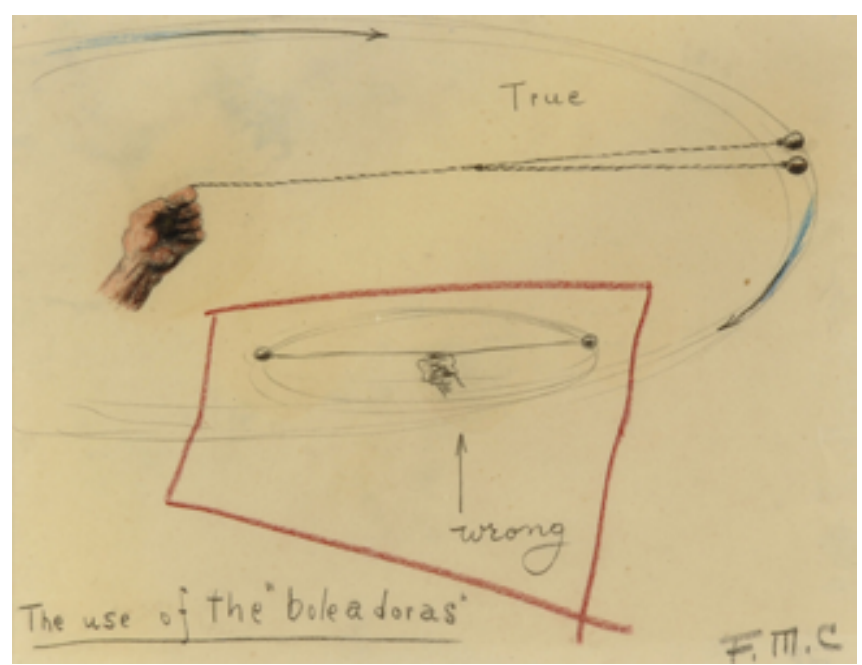

Figura 10. Florencio Molina Campos, El uso de las boleadoras, dibujo. Regis tro 1700, Fondo Florencio Molina Campos, Biblioteca del Museo Las Lilas de Areco, Provincia de Buenos Aires, Argentina.

Sin embargo, no incidió en nada respecto del carácter general de la narración: un uso humorístico que se le daba en el relato a ciertas costumbres de vida en el campo, para crear a través de ellas situaciones fantásticas, buscando seducir al público local.

La comicidad implícita en las mismas caricaturas que el artista había creado tomaron en esa transposición cultural y lingüística una dirección de sentido que las mismas imágenes habilitaban, pero que el propio creador no admitió. La utilización de costumbres y personajes rurales argentinos para crear escenas cómicas no estaba dentro de sus planes.
Precisamente, nos encontramos frente a ese punto sensible intrínseco a la obra de Molina Campos y tan peligroso por los deslizamientos de sentido que podía disparar. El destino del gaucho a una vida sufrida y en soledad, que lo ubicaba en la tradición cultural argentina como exponente universal de la dignidad frente a un drama humano, derivaba bajo la pluma del equipo Disney en las desopilantes vicisitudes entre Goofy gaucho y su "compañera" el caballo.

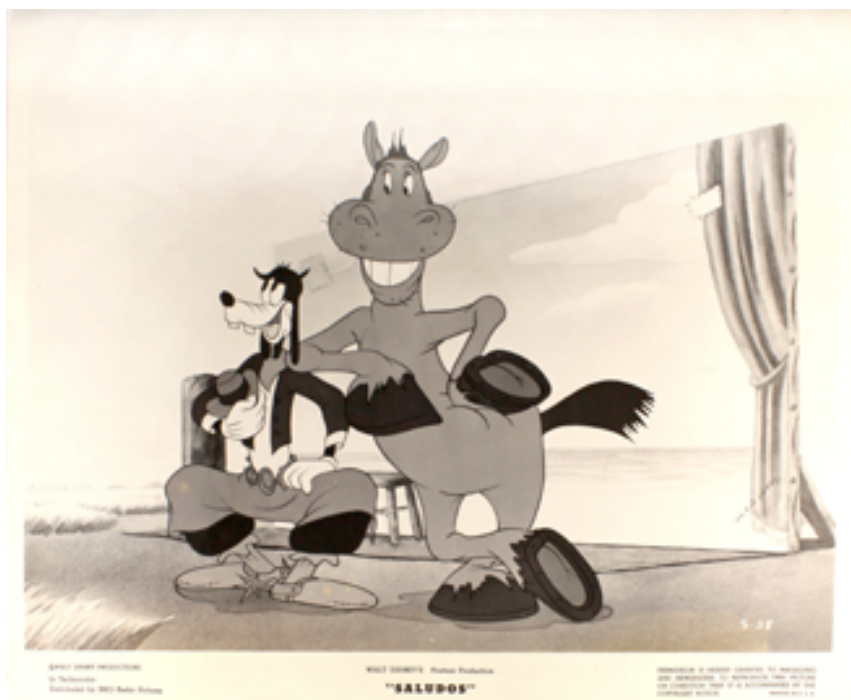

Figura 11. Walt Disney Productions, Saludos, fotograma del film Goofy se hace gaucho, 1942. Fondo Florencio Molina Campos, Biblioteca del Museo Las Lilas de Areco, Provincia de Buenos Aires, Argentina.

Si la caricatura, como sostiene Ernst Gombrich, apunta a codificar el aspecto ético/moral de un personaje o un tipo (Gombrich, 1996 [1990]: 338), las caricaturas de Molina Campos resultan verdaderamente ambiguas en la caracterización moral de los personajes que ilustra. El mismo género caricaturesco (que como sabemos viene del italiano caricare, cargar, burlar) no brinda ninguna garantía a la hora de plantear un diálogo intercultural de iguales; por el contrario, ha sido la técnica históricamente predilecta para tramitar las más ácidas disputas xenófobas (Gombrich, 1996 [1990]). Goofy se vuelve gaucho no hizo otra cosa más que llevar los límites más allá de lo tolerable. No es sorprendente que Fernando Ortiz Echagüe, en un artículo publicado en setiembre de 1942 en La Nación, lanzara comentarios mordaces con respecto a Saludos Amigos y los "gauchos cocoliches", frente a los cuales Molina Campos debió responder por carta utilizando su escasa participación en la producción del film como argumento para defenderse de las críticas (Ocampo, 2003: 76-79). El episodio tendría consecuencias en la obra posterior de Molina. 


\section{TRANSFORMACIONES EN LA OBRA DE MOLINA CAMPOS: EL CONTRATO DE LA MINNEAPOLIS MOLINE.}

En la Argentina, como mencionamos al principio, la obra de Molina Campos había circulado exclusivamente por circuitos comerciales o canales privados. Pero en Estados Unidos, la situación se modificó substancialmente. En el primer año de su estadía allí, la gran exhibición de obras realizada en la galería del English Book Shop de Nueva York le permitió entrar en contacto con el filántropo Edward Larocque Tinker, que se convirtió rápidamente en uno de los primeros coleccionistas y difusores de su obra, solicitándole para su colección de arte treinta dibujos de los allí expuestos con la temática los jinetes de las Américas. La colección fue posteriormente donada al Harry Randsom Center, de la Universidad de Texas en Austin. Su relación con Tinker le abrió camino además para ser contratado por empresas petroleras como ilustrador de afiches de cartelería publicitaria.

Debido a una serie de factores, los museos de bellas artes norteamericanos se abrieron hacia la producción cultural de masas - en relación a esta investigación, específicamente hacia el coleccionismo de cortos animados-, y esto también dio lugar a que las caricaturas de Molina Campos consiguieran por primera vez un espacio de legitimación en los museos.

Una de las primeras instituciones artísticas en abocarse a la exhibición y adquisición de cortos animados fue el Museo de Arte Moderno de Nueva York (MoMA). Con métodos similares a los de Alfred Barr, director del MoMA y curador en jefe del departamento de pintura y escultura, el departamento fílmico buscó establecer una narrativa histórica que ligara las contracorrientes artísticas entre Hollywood y Europa. Por lo tanto, la filmografía norteamericana se convirtió en una parte integral de la narrativa histórica del film (Mikulak, 1997: 37-41)

Dos problemas implícitos en su investigación resultan esenciales para enmarcar la admisión de la obra de Molina Campos en la escena artística norteamericana. En primer lugar, la coyuntura de la guerra que permitía que museos se tornaran mucho más permeables a los objetivos políticos gubernamentales. Los años de la segunda guerra mundial crearon las condiciones para que los museos redefinieran el género de los cortos animados como un medio ya no exclusivamente pensado para un público infantil, sino como un lenguaje con la potencialidad de transformarse en una forma de persuasión ideológica de los adultos. En segundo lugar, la aparición de ciertas estrategias en el circuito de galerías que buscaban potenciar el valor simbólico -y de suyo, el económico- de los films de animación. El dibujo y la pintura, dos bellas artes en las que se basaba la producción de cortos de animación, "proveyeron los objetos de carácter 'único' requeridos para que éstos ingresaran con derecho propio al mundo del arte, y allí pudieran ser en alguna medida asimilados." En 1938 el Museo de Arte Moderno exhibió por primera vez bocetos, dibujos, pinturas, celuloides y paisajes del estudio Disney, y coleccionó y archivó este tipo de materiales. (Mikulak, 1997: 68-69)

Esta iniciativa adoptada por el MoMA, institución líder en el campo de las bellas artes, contribuyó a que en los años cuarenta se generara un amplio consenso en la prensa y opinión pública respecto a la idea de que las caricaturas animadas eran una forma de expresión artística. A partir de ello muchos museos comenzaron a exhibir y/o coleccionar los bocetos originales realizados por los dibujantes de la empresa.
La invitación a exhibir algunas de sus caricaturas que el Museo de Arte de San Francisco extendiera a Molina Campos a comienzos de 1942 fue una oportunidad nueva y excepcional que se le presentó para obtener una legitimación artística de sus obras, en el contexto de una agenda curatorial absolutamente comprometida con la política de propaganda panamericanista del gobierno.

Molina Campos complació los requerimientos del envío que le solicitaron y entre las 29 obras despachadas, muchas fueron sus conocidas caricaturas de gauchos en situaciones habituales de la vida rural -entre faenas, ocio y vida privada-, realizadas en témpera y acuarela (Riña de gallos, La zamba, Acomodando el equipaje, Boleador de avestruz) y narradas de forma humorística a través de imagen y su correspondiente apoyatura textual. De hecho en ocasiones los títulos del check list en inglés eran extensos párrafos que buscaban anclar de forma más precisa el sentido de la imagen mediante diálogos imaginarios sostenidos por los personajes, a la manera de la primera serie de calendarios realizados para Alpargatas. ${ }^{5}$ Pero también envió algunos óleos en los que el paisaje por sí solo se tornaba protagonista y metáfora de la vida solitaria, simple y pacífica en las pampas. Es aparentemente alrededor de estos años (entre 1939 y 1942) cuando Molina Campos comenzó a trabajar también paisajes naturalistas en óleo sobre tela con o sin presencia humana, por lo que podemos conjeturar que el reconocimiento de su obra en el circuito de coleccionistas y museos fue un factor importante a la hora de decidirse a probar suerte con esta técnica. ${ }^{6}$

La modificación sustantiva del carácter de sus imágenes, en las que el paisaje y las costumbres de cada escena rural se tornan protagonistas por sobre los personajes en sí mismos, se percibe también en otro encargo comercial relevante que Molina Campos recibió en 1944, transitando ya el período final de la segunda guerra.

A comienzos de este año, el artista fue contratado por la compañía de maquinaria agrícola Minneapolis Moline Power Implement Corporation para ilustrar calendarios replicando el caso Alpargatas en Argentina. Como otras tantas empresas privadas durante la segunda guerra, la Minneapolis Moline vinculó su actividad a los objetivos patrióticos requeridos por el gobierno, estableciendo una alianza político-comercial que redundaría en beneficios económicos. ${ }^{7}$ Los calendarios de la Minneapolis Moline fueron publicados entre 1944 a 1958 , y retomando la modalidad utilizada en la primera serie de almanaques de Alpargatas publicados en Argentina, Molina Campos decidió que todos incluyeran un breve texto creado por el pintor para darle una inscripción narrativa ficcional a la imagen. ${ }^{8}$ Sin embargo, en este caso los textos estaban escritos en un español completamente neutral y no tenían el carácter humorístico y ficcional de los de Alpargatas. En segundo lugar, tanto imágenes como textos no se adscribieron específicamente al territorio argentino,

5 Lista de obras enviada por Molina Campos al San Francisco Museum of Art, traducidas al inglés por el mismo artista, mecanografiada, con anotaciones manuscritas y precios. ArchExho01 Box 18 Folder 1, SFMOMA Archives.

6 De acuerdo a Fernan Felix de Amador, Reposo, una escena nocturna rural de 1938, es el primer óleo creado por el artista, en el contexto de su nostalgia por la llanura pampeana que le produce su larga estadía en los Estados Unidos. Ver Félix de Amador, 1939. Archivo Fundación Molina Campos, Moreno, Buenos Aires.

7 S/f, "Promote "Good Neighbor" Policy", The Golden Valley News, Dakota del Norte, Estados Unidos, 16 de marzo de 1944. Registro 6267. Archivo Museo Las Lilas, San Antonio de Areco, Buenos Aires. El artículo iba ilustrado con dos obras de Molina Campos, Pa nuevos horizontes y Hospitalidad, cuyas resonancias diplomáticas son más que evidentes.

8 A partir de 1946, los relatos están escritos en inglés y en español. 
sino que representaron parajes rurales de toda América latina, incluyendo la zona andina. Y en tercer lugar, pueden discernirse modificaciones de carácter plástico: aparecen personajes que pierden la intensidad caricaturesca de los de Alpargatas, tanto en sus fisionomías como en sus dimensiones relativas al paisaje que los contiene, aunque mantienen una fuerte inscripción racial. La experiencia fallida de su participación en el proyecto de la Disney parece haber puesto en alerta a Molina Campos. La refuncionalización de sus caricaturas gauchescas en Estados Unidos había tenido un alto costo, habilitando la utilización de las costumbres de la vida del gaucho argentino en función del éxito comercial de los dibujos animados; y permitiendo la pérdida de su trascendencia moral. Creyendo que la exacerbada caricaturización de costumbres y vicios locales había de alguna forma alentado a la mirada extranjera a interpretar la vida rural en clave de comedia, en las ilustraciones para los calendarios de la Minneapolis Molina Campos matizó los rasgos fisiognómicos, moderando paulatinamente la caricaturización en muchas de las imágenes y componiendo escenas más equilibradas en cuanto a tamaños relativos entre figuras y paisaje y también en lo que respecta a la acción desarrollada en ellas, de manera tal de eludir aquellos efectos indeseados. Y así, recuperar el control de la interpretación de sus propias imágenes, fugadas del sendero significativo que Molina había imaginado para ellas.

Los últimos óleos realizados por el artista en la década del cincuenta, ya de regreso al país, como aquel que se encuentra actualmente en la colección del Museo de Arte del Tigre (MAT), mantuvieron estas características, y otros incorporaron inclusive cierto matiz moderno, mediante un estilo más sintético en el tratamiento del color y la representación de las figuras. Lejos de una fórmula fija, las imágenes de Molina Campos registraron modificaciones significativas a lo largo de su vida, dando cuenta de las circulaciones entre escenas conflictivas y cambiantes que recorrieron el artista y su obra. $9^{10}$

9 Agradezco muy especialmente a la directora de la Fundación Flo rencio Molina Campos en Moreno, provincia de Buenos Aires, señora Consuelo Güiraldes, y a Florencia Rui Diaz, por facilitarme importante documentación referida a la estancia de Molina Campos en los Estados Unidos, así como también por las conversaciones que mantuvimos en relación a la obra y vida del artista, que significaron un enriquecimiento a un borrador anterior del presente artículo. Asi mismo, agradezco a la bibliotecaria Luciana Falibene y al Museo Las Lilas en San Antonio de Areco por todo el material documental proporcionado de los proyectos artísticos de Molina Campos en los Estados Unidos.

$10 \quad$ Este artículo integra las investigaciones del proyecto Modernidd(es) Descentralizada(s): arte, política y contracultura en el eje trasatlántico durante la Guerra Fría 2, financiado por la secretaría de Estado de Investigación, Desarrollo e Innovación, Ministerio de Economía y Competitividad, España. Resolución HAR2017-82755-P. 
Adamovsky, E. (2019). El gaucho indómito. De Martín Fierro a Perón, el emblema imposible de una nación desgarrada. Buenos Aires: Siglo XXI.

Adams, D. (2007). Saludos Amigos: Hollywood and FDR's Good Neighbor Policy. Quarterly Review of Film and Video, 24(3), 289-295, DOI: 10.1080/10509200500486395.

Bonomini, Á. (1989). Arte y testimonio, en Florencio Molina Campos, Cat. Exp. Buenos Aires: MNBA.

Casas, M. (2017). Las metamorfosis del gaucho. Círculos criollos, tradicionalistas y política en la provincia de Buenos Aires 1930-1960. Buenos Aires: Prometeo.

Cramer, G., Prutsch, U. (eds.) (2012). ¡Américas Unidas! Nelson A. Rockefeller's Office of Inter-American Affairs (1940-1946). Madrid: Iberoamericana Vervuert.

DaCosta Kaufmann, T., Dossin C., Joyeux-Prunel B. (eds.) (2017). Circulations in the Global History of Art, London / New York: Routledge.

Erskine, J. (24 de febrero de 1942). The goodwill tour of don Florencio de la Pampa. Liberty 19 (4) Registro 1158, Archivo Museo Las Lilas, San Antonio de Areco, Argentina.

Félix de Amador, F. (diciembre 1939). Gauchos y paisajes de Molina Campos, AD 1, 10-11. Archivo Fundación Molina Campos, Moreno, Buenos Aires.

Gilberto Joseph, Catherine Legrand, Ricardo Salvatore (eds.) (1998). Close Encounters of Empire: Writing the Cultural History of US-Latin American Relations. Durham: Duke University Press Books.

Gombrich, E. (1996) [1990]. Magic, Mith and Metaphor: Reflections on Pictorial Satire. En: Woodfield, R., ed. The Essencial Gombrich. Londres: Phaidon, 331-353.

Gutiérrez Zaldívar, I. (2004). Molina Campos en Mendoza. Buenos Aires: Zurbarán.

Kaufman, J. B. (2009). South of the Border with Disney. Walt Disney and the Good Neighbor Program, 1941-1948. New York: Disney Editions.

Mikulak, B. (1997). Mickey Meets Mondrian: Cartoons Enter the Museum of Modern Art. Cinema Journal, 36 (3), 37-41.

Molina, E. (9 de abril de 1989). Pampa y memoria. Página 12 Suplemento Cultural, 2-3.

Monzón, H. Florencio Molina Campos. Documento sin referencia en carpeta de artista, Archivo Biblioteca, MNBA, Buenos Aires.

Ocampo, J.C. (2003). Florencio Molina Campos. Moreno: Fundación Florencio Molina Campos.

Paquette, C. (2002). Public Duties, Private Interests: Mexican Art at New York's Museum of Modem Art, 1929-1954. Dissertation thesis. Santa Barbara: University of California.

Ponce Aguirre, M.E. (1989). Florencio Molina Campos en mi vida. Moreno: edición del autor.

Tota, Antonio (2000). O imperialismo sedutor. A americanizaçao do Brasil na época da Segunda Guerra. São Paulo: Companhia Das Letras.

Woll, A.L. (1974). Hollywood's Good Neighbor Policy. Journal of Popular Film, 3(4), 278-293, DOI: $10.1080 / 00472719.1974 .10661742$ 
